\title{
Retinal artery and vein thrombotic occlusion during pregnancy: markers for familial thrombophilia and adverse pregnancy outcomes
}

This article was published in the following Dove Press journal:

Clinical Ophthalmology

23 May 2016

Number of times this article has been viewed

\section{Will S Kurtz' \\ Charles J Glueck' \\ Robert K Hutchins ${ }^{2,3}$ \\ Robert A Sisk ${ }^{2,3}$ \\ Ping Wang ${ }^{\prime}$}

'Cholesterol, Metabolism, and Thrombosis Center, Jewish Hospital of Cincinnati, ${ }^{2}$ Cincinnati Eye Institute, ${ }^{3}$ Department of Ophthalmology, University of Cincinnati College of Medicine, Cincinnati, Ohio, USA
Correspondence: Charles J Glueck Cholesterol, Metabolism, and Thrombosis Center, Jewish Hospital of Cincinnati, Suite 430, 2135 Dana Avenue, Cincinnati OH 45207, USA

$\mathrm{Tel}+\mathrm{I} 5139248250$

Fax + I 5139248273

Email cjglueck@mercy.com
Background: Ocular vascular occlusion (OVO), first diagnosed during or immediately after giving birth, often reflects superposition of the physiologic thrombophilia of pregnancy on previously undiagnosed underlying familial or acquired thrombophilia associated with spontaneous abortion, eclampsia, or maternal thrombosis.

Specific aim: We describe OVO, first diagnosed during pregnancy or immediately postpartum, in three young females (ages $32,35,40$ ) associated with previously undiagnosed familial thrombophilia.

Results: Branch retinal artery occlusion (BRAO) occurred at 9 and 13 weeks gestation in two females, aged 32 and 35 . Central retinal vein occlusion occurred immediately postpartum in a 40-year-old. One of the two females with BRAO subsequently developed eclampsia, and one had a history of unexplained first trimester spontaneous abortion. All three females were found to have previously unexplained familial thrombophilia. The two females with BRAO had low first trimester free protein S 42 (41\%), lower normal limit (50\%), and one of these two had high factor VIII (165\%, upper normal limit 150\%). The woman with central retinal vein occlusion had high factor XI (169\%, upper normal limit 150\%). Enoxaparin (40-60 mg/day) was started and continued throughout pregnancy in both females with BRAO to prevent maternal-placental thrombosis, and of these two females, one had an uncomplicated pregnancy course and term delivery, and the second was at gestational week 22 without complications at the time of this manuscript. There were no further OVO events in the two females treated with enoxaparin or in the untreated patient with postpartum eclampsia.

Conclusion: OVO during pregnancy may be a marker for familial or acquired thrombophilia, which confers increased thrombotic risk to the mother and pregnancy, associated with spontaneous abortion or eclampsia. OVO during pregnancy, particularly when coupled with antecedent adverse pregnancy outcomes, should prompt urgent thrombophilia evaluation and institution of thromboprophylaxis to prevent adverse maternal and fetal-placental thrombotic events.

Keywords: thrombophilia, ocular thrombosis, retinal vascular occlusion, CRVO, BRAO, pregnancy, miscarriage, fetal loss, ocular vascular occlusion, pre-eclampsia, eclampsia

\section{Introduction}

Retinal vascular occlusion (RVO) includes central retinal vein occlusion (CRVO) and branch RVO, central retinal artery occlusion and branch retinal artery occlusion (BRAO), amaurosis fugax, and non-arteritic ischemic optic neuropathy. ${ }^{1-5} \mathrm{CRVO}$-branch $\mathrm{RVO}^{6-8}$ and central retinal artery occlusion-BRAO ${ }^{2,4,9-13}$ are commonly associated with thrombophilia in young patients, ${ }^{2-6,9,14-20}$ and visual consequences can be severe. ${ }^{21}$ Carotid artery atherosclerosis is the most common etiology for central retinal artery occlusion 
and BRAO, with embolization of a portion of atherosclerotic plaque from the ipsilateral carotid artery to the retinal artery. ${ }^{22-24}$ However, this is unusual for patients under 40 in whom a cardiogenic embolic source is more common. ${ }^{25,26}$

Three cases of RVO have been reported during normal pregnancy, ${ }^{27-29}$ one case during pregnancy complicated by pre-eclampsia, ${ }^{30}$ and one postpartum after a pre-eclamptic pregnancy. ${ }^{31} \mathrm{CRVO}$ or retinal artery occlusion may result from the interaction between inherited and acquired thrombophilia-hypofibrinolysis and the physiologic thrombophilia of pregnancy, ${ }^{6}$ where a hyper-estrogenic hypercoagulable state appears to be a physiological adaptive mechanism $^{32}$ to prevent postpartum hemorrhage. ${ }^{33}$

Pregnancy by itself increases the risk of thrombosis four- to fivefold, ${ }^{33}$ and the thrombogenic potential of inherited disorders is thus enhanced during pregnancy. Heterozygosity for factor V Leiden mutation increases the risk of clotting approximately eightfold, and combined with the thrombophilia of pregnancy, the aggregate combined risk of thrombosis may be $\sim 40$ times greater than that of the general population. ${ }^{14,15,34}$ In addition to ocular vascular occlusion, pregnant patients with familial or acquired thrombophilia are also at increased risk for recurrent fetal loss, and thrombotic morbidity and mortality. ${ }^{35}$

Our specific aim in the current report was to describe ocular thrombosis first appearing during pregnancy or immediately postpartum in three young females associated with previously undiagnosed familial thrombophilia.

\section{Methods}

The study was approved by the Cincinnati, Ohio Jewish Hospital Institutional Review Board (ID 12-03). Written informed consent was obtained from patients after the nature of the study was fully explained. The study was conducted in accordance with the tenets of the Declaration of Helsinki.

Three Caucasian females who developed ocular vascular occlusion during pregnancy or early postpartum were referred to us in 2015 by vitreoretinal specialists from the Cincinnati Eye Institute. The diagnoses were established by retinologists through complete ophthalmological evaluations that documented the stereotypical features of retinal vein or artery occlusion on detailed fundus exam. As summarized in Table 1, detailed assessment for thrombophilia and hypofibrinolysis was carried out in blood obtained in the morning from seated patients following published methods. ${ }^{16}$

\section{Case reports}

\section{Case I}

A 35-year-old nonsmoking female presented with sector visual field loss from a BRAO left eye at 8 weeks gestation,
Table I Measures of thrombophilia and hypofibrinolysis ${ }^{8,16,51}$ important in the diagnosis of retinal vein and artery thrombosis

PCR assays:

Thrombophilia: Factor V Leiden, G20210A Prothrombin gene, MTHFR C677T and AI298C

Hypofibrinolysis: 4G4G mutation of the plasminogen activator inhibitor-I gene

Serologic assays:

Thrombophilia; Homocysteine, anticardiolipin antibodies immunoglobulin (Ig)G and IgM, lupus anticoagulant, resistance to activated protein C, factors VIII, XI, antigenic proteins C, S (total and free), and antithrombin III

Abbreviation: PCR, polymerase chain reaction.

having developed a persistent "after" image when she looked at the sun. She had one previous unexplained spontaneous first trimester abortion and three uneventful live births. There was no previous history of pulmonary embolus or deep venous thrombosis, estrogen-progestin oral contraceptive, or hormone use. At 10 weeks gestation, evaluation for thrombophilia revealed free protein S deficiency (42\%, first trimester laboratory lower normal limit 50\%). At 10 weeks gestation, she was started on enoxaparin $40 \mathrm{mg}$ twice per day, and later switched to enoxaparin $40 \mathrm{mg}$ once per day as prophylaxis against further ocular thrombosis or maternal and placental thrombosis during pregnancy. She has finished gestational week 22 with no complications at the time of publication.

\section{Case 2}

A 32-year-old nonsmoking female presented with BRAO right eye at 13 weeks gestation in her first pregnancy. Family history was significant for deep venous thrombosis and lethal pulmonary embolus in the maternal grandmother, although the patient had no prior thrombotic events. Evaluation for thrombophilia-hypofibrinolysis revealed free protein $\mathrm{S}$ deficiency (41\%, first trimester lower normal limit 50\%) and high factor VIII (165\%, upper normal limit 150\%). She was started on enoxaparin $1.5 \mathrm{mg} / \mathrm{kg}$ per day in two divided doses, later switched to $40 \mathrm{mg}$ od. By 20 weeks of pregnancy, her loss of vision from the BRAO was much diminished. After developing eclampsia at 37 weeks, she delivered a healthy child via emergency $\mathrm{C}$-section at 37 weeks due to significant hypotension and drop in fetal heart rate after epidural anesthesia.

\section{Case 3}

A 55-year-old Caucasian female smoker with a history of hypertension, sarcoidosis, and hypercholesterolemia presented with CRVO left eye. She had an unexplained first trimester miscarriage at age 16. At age 40 (second pregnancy), 
4 days after the birth of her son, she had an episode of left eye "haziness" that resolved over 3 months without ophthalmologic diagnosis. Two weeks prior to her visit at our center at age 55, she developed the same "haziness" and was found to have CRVO OS. She had no history of deep venous thrombosis or pulmonary embolus and had quit smoking at age 53. Evaluation for thrombophilia-hypofibrinolysis revealed high factor XI (169\%, upper normal limit 150\%).

\section{Discussion}

Retinal vein occlusion is the second most common RVO and a major threat to vision. ${ }^{21}$ Thrombophilia commonly contributes to the development of retinal vein occlusion in patients under 50 years of age, ${ }^{6-8}$ especially those without typical risk factors of hypertension, diabetes mellitus, or glaucoma. ${ }^{3,4,6,9,14,16}$ Retinal artery thrombosis, when not associated with carotid artery disease, ${ }^{36}$ Behçets disease, ${ }^{37,38}$ or antiphospholipid antibody syndrome, ${ }^{13}$ is commonly caused by familial thrombophilia and hypofibrinolysis. ${ }^{2,4,9-13}$ Neither retinal vein nor artery occlusion has been reported associated with thrombophilic mutations in the thrombomodulin gene, ${ }^{39,40}$ which have been associated with venous thromboembolism in Chinese. ${ }^{40}$ Not measuring thrombomodulin gene mutations ${ }^{40}$ was a limitation of our paper.

When the physiologic thrombophilia of pregnancy ${ }^{32}$ or the postpartum period ${ }^{41}$ is superimposed on underlying familial thrombophilia, risk of thrombosis and ocular thrombosis ${ }^{9}$ is substantially increased.

Free protein $\mathrm{S}$ levels during the first trimester of pregnancy are broadly comparable to preconception levels, but fall sharply in the second trimester. ${ }^{42,43}$ Our two patients with familial protein $\mathrm{S}$ deficiency had first trimester free protein $\mathrm{S}$ levels of $42 \%$ and $41 \%$, well below our laboratory first trimester lower normal limit ${ }^{42,43}$ of $50 \%$.

Park et $\mathrm{a}^{21}$ reported higher RVO incidence and sexual predilection in Korean females at peak childbearing years aged 20-29 compared to those ages $<20$ years or older than 29 years. Subsequently, Park et $\mathrm{al}^{44}$ suggested that pre-eclampsia/eclampsia "was a risk factor for RVO, while pregnancy itself may not be a risk factor for RVO." We speculate, however, that thrombophilia concurrently underlies both $\mathrm{RVO}^{2-4,6,9-14,16}$ and pre-eclampsia/eclampsia ${ }^{4,11-13,45}$ since it is known to be an underlying etiology for both.

We have previously reported that many patients referred to our center with amaurosis fugax, non-arteritic ischemic optic neuropathy, retinal artery occlusion, and retinal vein occlusion have an underlying familial thrombophilia. . $^{6,9,14-16,34}$ Two of our current three patients had unexplained spontaneous miscarriage, and one had eclampsia, closely associated with thrombophilia, ${ }^{46}$ while still on enoxaparin therapy at 37 weeks gestation. When retinal artery or retinal vein occlusion occur during pregnancy or in the puerperium, diagnosis of ocular vascular occlusion should prompt an urgent evaluation for underlying thrombophiliahypofibrinolysis syndromes. The diagnosis of an underlying thrombophilia is important not only for the management of RVO but also for the success of the pregnancy, allowing timely thromboprophylaxis ${ }^{47-50}$ to prevent maternal thrombosis and pregnancy loss.

\section{Disclosure}

The authors report no conflicts of interest in this work.

\section{References}

1. Kuo JZ, Lai CC, Ong FS, et al. Central retinal vein occlusion in a young Chinese population: risk factors and associated morbidity and mortality. Retina. 2010;30:479-484.

2. Marcucci R, Sodi A, Giambene B, et al. Cardiovascular and thrombophilic risk factors in patients with retinal artery occlusion. Blood Coagul Fibrinolysis. 2007;18:321-326.

3. Marcucci R, Sofi F, Grifoni E, Sodi A, Prisco D. Retinal vein occlusions: a review for the internist. Intern Emerg Med. 2011;6:307-314.

4. Sottilotta G, Oriana V, Latella C, et al. Role of hyperhomocystinemia in retinal vascular occlusive disease. Clin Appl Thromb Hemost. 2007; 13:104-107.

5. Sottilotta G, Siboni SM, Latella C, et al. Hyperhomocysteinemia and C677T MTHFR genotype in patients with retinal vein thrombosis. Clin Appl Thromb Hemost. 2010;16:549-553.

6. Schockman S, Glueck CJ, Hutchins RK, Patel J, Shah P, Wang P. Diagnostic ramifications of ocular vascular occlusion as a first thrombotic event associated with factor $\mathrm{V}$ Leiden and prothrombin gene heterozygosity. Clin Ophthalmol. 2015;9:591-600.

7. Risse F, Frank RD, Weinberger AW. Thrombophilia in patients with retinal vein occlusion: a retrospective analysis. Ophthalmologica. 2014; 232:46-52.

8. Mrad M, Fekih-Mrissa N, Wathek C, Rannen R, Gabsi S, Gritli $\mathrm{N}$. Thrombophilic risk factors in different types of retinal vein occlusion in Tunisian patients. $J$ Stroke Cerebrovasc Dis. 2014;23: 1592-1598

9. Glueck CJ, Ping W, Hutchins R, Petersen MR, Golnik K. Ocular vascular thrombotic events: central retinal vein and central retinal artery occlusions. Clin Appl Thromb Hemost. 2008;14:286-294.

10. Glueck CJ, Tracy T, Wang P. Legg-Calve-Perthes disease, venous and arterial thrombi, and the factor $\mathrm{V}$ Leiden mutation in a four-generation kindred. J Pediatr Orthop. 2007;27:834-837.

11. Leifert D, Auw-Hadrich C, Leifert JA. [Arterial ocular occlusion associated with systemic venous thrombophilia - 2 case reports]. Klin Monbl Augenheilkd. 2006;223:908-913. German.

12. Salomon O, Huna-Baron R, Moisseiev J, et al. Thrombophilia as a cause for central and branch retinal artery occlusion in patients without an apparent embolic source. Eye (Lond). 2001;15:511-514.

13. Bick RL. Antiphospholipid thrombosis syndromes. Clin Appl Thromb Hemost. 2001;7:241-258.

14. Glueck CJ, Wang P, Bell H, Rangaraj V, Goldenberg N. Associations of thrombophilia, hypofibrinolysis, and retinal vein occlusion. Clin Appl Thromb Hemost. 2005; 11:375-389.

15. Glueck CJ, Goldenberg N, Bell H, Golnik K, Wang P. Amaurosis fugax: associations with heritable thrombophilia. Clin Appl Thromb Hemost. $2005 ; 11: 235-241$

16. Glueck CJ, Hutchins RK, Jurantee J, Khan Z, Wang P. Thrombophilia and retinal vascular occlusion. Clin Ophthalmol. 2012;6:1377-1384. 
17. Dori D, Beiran I, Gelfand Y, et al. Multiple retinal arteriolar occlusions associated with coexisting primary antiphospholipid syndrome and factor V Leiden mutation. Am J Ophthalmol. 2000;129:106-108.

18. Golub BM, Sibony PA, Coller BS. Protein S deficiency associated with central retinal artery occlusion. Arch Ophthalmol. 1990;108:918.

19. Greven CM, Weaver RG, Owen J, Slusher MM. Protein S deficiency and bilateral branch retinal artery occlusion. Ophthalmology. 1991;98: 33-34.

20. Talmon T, Scharf J, Mayer E, Lanir N, Miller B, Brenner B. Retinal arterial occlusion in a child with factor $\mathrm{V}$ Leiden and thermolabile methylene tetrahydrofolate reductase mutations. Am J Ophthalmol. 1997; 124:689-691.

21. Park SJ, Choi NK, Park KH, Woo SJ. Nationwide incidence of clinically diagnosed retinal vein occlusion in Korea, 2008 through 2011: preponderance of women and the impact of aging. Ophthalmology. 2014; 121:1274-1280.

22. Ahuja RM, Chaturvedi S, Eliott D, Joshi N, Puklin JE, Abrams GW. Mechanisms of retinal arterial occlusive disease in African American and Caucasian patients. Stroke. 1999;30:1506-1509.

23. Brown GC, Magargal LE, Shields JA, Goldberg RE, Walsh PN. Retinal arterial obstruction in children and young adults. Ophthalmology. 1981; $88: 18-25$.

24. Greven CM, Slusher MM, Weaver RG. Retinal arterial occlusions in young adults. Am J Ophthalmol. 1995;120:776-783.

25. Recchia FM, Brown GC. Systemic disorders associated with retinal vascular occlusion. Curr Opin Ophthalmol. 2000;11:462-467.

26. Sharma S, Sharma SM, Cruess AF, Brown GC. Transthoracic echocardiography in young patients with acute retinal arterial obstruction. RECO Study Group. Retinal Emboli of Cardiac Origin Group. Can J Ophthalmol. 1997;32:38-41.

27. Chew EY, Trope GE, Mitchell BJ. Diurnal intraocular pressure in young adults with central retinal vein occlusion. Ophthalmology. 1987; 94:1545-1549.

28. Gabsi S, Rekik R, Gritli N, Naili K, Hassoumi MH. [Occlusion of the central retinal vein in a 6-month pregnant woman]. J Fr Ophtalmol. 1994;17:350-354. French.

29. McLoone EM, Best RM. Pregnancy-related papillophlebitis. Eur J Ophthalmol. 2004;14:65-66.

30. Gonzalvo FJ, Abecia E, Pinilla I, Izaguirre LB, Olivan JM, Honrubia FM. Central retinal vein occlusion and HELLP syndrome. Acta Ophthalmol Scand. 2000;78:596-598.

31. Rahman I, Saleemi G, Semple D, Stanga P. Pre-eclampsia resulting in central retinal vein occlusion. Eye (Lond). 2006;20:955-957.

32. Eldor A. Thrombophilia, thrombosis and pregnancy. Thromb Haemost. 2001;86:104-111.

33. James AH. Thrombosis in pregnancy and maternal outcomes. Birth Defects Res C Embryo Today. 2015;105:159-166.

34. Glueck CJ, Wang P, Bell H, Rangaraj V, Goldenberg N. Nonarteritic anterior ischemic optic neuropathy: associations with homozygosity for the C677T methylenetetrahydrofolate reductase mutation. J Lab Clin Med. 2004;143:184-192.

35. Glueck CJ, Pranikoff J, Aregawi D, et al. The factor V Leiden mutation, high factor VIII, and high plasminogen activator inhibitor activity: etiologies for sporadic miscarriage. Metabolism. 2005;54:1345-1349.

Clinical Ophthalmology

\section{Publish your work in this journal}

Clinical Ophthalmology is an international, peer-reviewed journal covering all subspecialties within ophthalmology. Key topics include: Optometry; Visual science; Pharmacology and drug therapy in eye diseases; Basic Sciences; Primary and Secondary eye care; Patient Safety and Quality of Care Improvements. This journal is indexed on Submit your manuscript here: http://www.dovepress.com/clinical-ophthalmology-journal
36. Lee J, Kim SW, Lee SC, Kwon OW, Kim YD, Byeon SH. Co-occurrence of acute retinal artery occlusion and acute ischemic stroke: diffusionweighted magnetic resonance imaging study. Am J Ophthalmol. 2014; 157:1231-1238

37. Ozdal PC, Ortac S, Taskintuna I, Teke MY, Firat E. Central retinal artery occlusion associated with ocular Behcet's disease. Eur J Ophthalmol. 2002;12:328-330.

38. Tian G, Lu N, Yan R, Zhang X. Central retinal artery occlusion and recurrent papillitis in a patient with incomplete Behcet disease. $J \mathrm{Neu}$ roophthalmol. 2011;31:244-247.

39. Kunz G, Ohlin AK, Adami A, Zoller B, Svensson P, Lane DA. Naturally occurring mutations in the thrombomodulin gene leading to impaired expression and function. Blood. 2002;99:3646-3653.

40. Tang L, Wang HF, Lu X, et al. Common genetic risk factors for venous thrombosis in the Chinese population. Am J Hum Genet. 2013; 92:177-187.

41. Kamel H, Navi BB, Sriram N, Hovsepian DA, Devereux RB, Elkind MS. Risk of a thrombotic event after the 6-week postpartum period. $N$ Engl J Med. 2014;370:1307-1315.

42. Faught W, Garner P, Jones G, Ivey B. Changes in protein C and protein S levels in normal pregnancy. Am J Obstet Gynecol. 1995;172: 147-150.

43. Szecsi PB, Jorgensen M, Klajnbard A, Andersen MR, Colov NP, Stender S. Haemostatic reference intervals in pregnancy. Thromb Haemost. 2010;103:718-727.

44. Park SJ, Choi NK, Seo KH, Park KH, Woo SJ. Retinal vein occlusion and pregnancy, pre-eclampsia, and eclampsia: the results from a nationwide, population-based study using the national claim database. PLoS One. 2015;10:e0120067.

45. Ascaso FJ, Padgett E, Grzybowski A. Re: Thrombophilic risk factors are uncommon in young patients with retinal vein occlusion. Retina. 2015;35:e21-e22.

46. Fong FM, Sahemey MK, Hamedi G, et al. Maternal genotype and severe preeclampsia: a HuGE review. Am J Epidemiol. 2014;180:335-345.

47. Grandone E, De Stefano V, Rossi E, Cappucci F, Colaizzo D, Margaglione M. Antithrombotic prophylaxis during pregnancy in women with deficiency of natural anticoagulants. Blood Coagul Fibrinolysis. 2008;19:226-230.

48. Ramidi G, Khan N, Glueck CJ, Wang P, Goldenberg N. Enoxaparinmetformin and enoxaparin alone may safely reduce pregnancy loss. Transl Res. 2009;153:33-43.

49. Brenner B. Thrombophilia and pregnancy loss in first intended pregnancy. J Thromb Haemost. 2005;3:2176-2177.

50. Middeldorp S. How I treat pregnancy-related venous thromboembolism. Blood. 2011;118:5394-5400.

51. GlueckCJ, Freiberg RA, Wang P. Heritable thrombophilia-hypofibrinolysis and osteonecrosis of the femoral head. Clin Orthop Relat Res. 2008;466: 1034-1040.

\section{Dovepress}

PubMed Central and CAS, and is the official journal of The Society of Clinical Ophthalmology (SCO). The manuscript management system is completely online and includes a very quick and fair peer-review system, which is all easy to use. Visit http://www.dovepress.com/ testimonials.php to read real quotes from published authors. 